Communication

\title{
Chiral $\beta$-Amino Alcohols as Ligands for the Ruthenium-Catalyzed Asymmetric Transfer Hydrogenation of $N$-Phosphinyl Ketimines
}

\section{Óscar Pablo, David Guijarro * and Miguel Yus *}

Departamento de Química Orgánica, Facultad de Ciencias and Instituto de Síntesis Orgánica (ISO), Universidad de Alicante, Apdo. 99, 03080 Alicante, Spain

* Authors to whom correspondence should be addressed; E-Mails: dguijarro@ua.es (D.G.); yus@ua.es (M.Y.); Tel.: +34-9-6590-3548; Fax: +34-9-6590-3549.

Received: 1 November 2011; in revised form: 22 December 2011 / Accepted: 28 December 2011 / Published: 9 January 2012

\begin{abstract}
Some chiral $\beta$-amino alcohols have been evaluated as potential ligands for the ruthenium-catalyzed asymmetric transfer hydrogenation (ATH) of $N$-phosphinyl ketimines in isopropyl alcohol. The ruthenium complex prepared from $\left[\mathrm{RuCl}_{2}(p \text {-cymene) }]_{2}\right.$ and $(1 S, 2 R)$-1-amino-2-indanol has shown to be an efficient catalyst for the ATH of several $\mathrm{N}$-(diphenylphosphinyl)imines, affording the reduction products in very good isolated yields and enantiomeric excesses up to $82 \%$. The inherent rigidity of the indane ring system present in the ligand seems to be very important to achieve good enantioselectivities.
\end{abstract}

Keywords: $N$-(diphenylphosphinyl)imine; asymmetric transfer hydrogenation; ruthenium catalyst; $\beta$-amino alcohol; isopropyl alcohol

\section{Introduction}

Amines are very important targets in organic chemistry since they are key substrates in organic synthesis, as well as in pharmaceutical and agrochemical research fields. In addition, chiral amines have been extensively used as resolving agents [1-4], starting materials for the preparation of therapeutic drugs [5] and chiral auxiliaries in asymmetric synthesis [6-8]. Due to this, synthetic chemists have made great efforts in order to implement efficient procedures for the preparation of chiral amines $[9,10]$ among which the reduction of iminic substrates plays a capital role. In recent 
years, the asymmetric transfer hydrogenation (ATH) has emerged as a powerful, convenient and wide-spread methodology to perform the reduction of $C=X$ bonds $(X=O$ or NR) [11] and it has become the second most used reduction methodology for this kind of functional group, just behind hydrogenations with molecular hydrogen. The ATH protocol presents several advantages: it is operationally simple, proceeds under mild reaction conditions, generally uses low catalyst loadings and avoids the handling of hazardous chemicals such as metallic hydrides or hydrogen gas. The ATH of prochiral ketones affords enantiomerically enriched secondary alcohols with excellent results [12-19]. Nevertheless, the asymmetric reduction of iminic compounds by transfer hydrogenation yielding chiral amines still remains underdeveloped and represents a challenging objective [20,21].

Due to the low electrophilic character of the iminic carbon, substrates in which the nitrogen atom is bonded to an activating group (aryl, alkoxy, amino, sulfinyl, sulfonyl or phosphinyl) are generally used in reduction methodologies leading to chiral amines. The phosphinyl group is very attractive since its removal from the reduction products can be conveniently achieved under mild acidic conditions, leading to the free primary amines [22,23]. $N$-phosphinyl imines have found a variety of synthetic applications in asymmetric processes [10,24,25]. For instance, the preparation of chiral amines can be achieved by stereoselective reduction of $\mathrm{N}$-phosphinyl ketimines through different synthetic approaches such as hydrogenation [26-28], hydrosilylation [29-33], Meerwein-Schmidt-PonndorfVerley (MSPV) reaction [34] or the use of boron [35] and aluminium hydrides [36].

Although the transfer hydrogenation protocol has been already applied to the reduction of different iminic substrates bearing alkyl [18], benzyl [17,18], aryl [17,18], sulfonyl [13,18,37] or sulfinyl [38-41] groups attached to the nitrogen atom, there are only a few examples on the use of $N$-phosphinyl imines as substrates $[18,42]$. In the last years, we have been interested in the use of $\beta$-amino alcohols as ligands for ruthenium complexes used as catalysts for the ATH of imines, especially $N$-(tert-butylsulfinyl)imines [38-41]. Since, to the best of our knowledge, the use of $\beta$-amino alcohols as chiral ligands has not been reported so far for the ATH of $N$-(diphenylphosphinyl)imines, we became interested in trying to apply our methodology to those substrates. Thereby, herein we present our preliminary results on the reduction of phosphinyl imines in isopropyl alcohol with ruthenium complexes bearing chiral $\beta$-amino alcohols.

\section{Experimental Section}

\subsection{General}

All glassware was dried in an oven at $100{ }^{\circ} \mathrm{C}$ and cooled to room temperature under argon before use. All reactions were carried out under an argon atmosphere. Ketone oximes were prepared according to a literature procedure [43]. Commercially available triethylamine, chlorodiphenylphosphine, $\left[\mathrm{RuCl}_{2}(p \text {-cymene })\right]_{2}$, ligand $\mathbf{L 1}$ and the anhydrous solvents $\mathrm{CH}_{2} \mathrm{Cl}_{2}, \mathrm{Et}_{2} \mathrm{O}$ and $i$-PrOH were used as received. Potassium tert-butoxide was heated in a Kugel-Rohr apparatus at $170-180{ }^{\circ} \mathrm{C}$ under vacuum for $4 \mathrm{~h}$ before use. Column chromatography was performed with silica gel 60 of 230-400 mesh. When mentioned, purification by column chromatography on deactivated silica gel means that, before adding the reaction crude to the column, the latter was washed with a mixture of 5\% triethylamine in hexane until the eluent coming from the column was basic according to $\mathrm{pH}$ paper. Thin layer chromatography 
(TLC) was performed on precoated silica gel plates (Merck 60, F254, $0.25 \mathrm{~mm}$ ); detection was done by UV254 light and staining with phosphomolybdic acid (solution of $1 \mathrm{~g}$ of phosphomolybdic acid in $24 \mathrm{~mL}$ of absolute ethanol); $R_{\mathrm{f}}$ values are given under these conditions. When mentioned, an $R_{\mathrm{f}}$ value measured on deactivated silica gel means that the TLC plate was eluted with a mixture of $5 \%$ triethylamine in hexane and dried before applying the sample. Melting points (mp) are uncorrected and were measured on a Reichert Thermovar apparatus. NMR spectra were recorded on a Bruker AC-300 spectrometer using, as internal references, tetramethylsilane (TMS) for ${ }^{1} \mathrm{H} \mathrm{NMR}$ and $\mathrm{CDCl}_{3}$ for ${ }^{13} \mathrm{C} \mathrm{NMR}$; chemical shifts are given in $\delta(\mathrm{ppm})$ and coupling constants $(J)$ in $\mathrm{Hz}$, unless otherwise stated. NMR samples were prepared using $\mathrm{CDCl}_{3}$ or $\mathrm{C}_{6} \mathrm{D}_{6}$ as solvent. Infrared (FT-IR) spectra were obtained on a Nicolet 510 P-FT spectrophotometer. Mass spectra (EI) were obtained at $70 \mathrm{eV}$ on a Hewlett Packard HP-5890 GC/MS instrument equipped with a HP-5972 selective mass detector. Optical rotations were measured on a Perkin-Elmer 341 polarimeter. HPLC analyses were performed at $25{ }^{\circ} \mathrm{C}$ on a JASCO apparatus, equipped with a PU-2089 Plus pump, a MD-2010 Plus detector and an AS-2059 Plus automatic injector.

\subsection{Procedure for the Preparation of N-Phosphinylimines 1}

Triethylamine $(1.35 \mathrm{~mL}, 10.5 \mathrm{mmol})$ was added to a solution of the ketone oxime $(10 \mathrm{mmol})$ in anhydrous $\mathrm{CH}_{2} \mathrm{Cl}_{2}(25 \mathrm{~mL})$ and $\mathrm{Et}_{2} \mathrm{O}(50 \mathrm{~mL})$ under argon and the solution was cooled to $-45^{\circ} \mathrm{C}$. A solution of chlorodiphenylphosphine $(1.87 \mathrm{~mL}, 10 \mathrm{mmol})$ in $\mathrm{CH}_{2} \mathrm{Cl}_{2}(3 \mathrm{~mL})$ was added dropwise over a period of $45 \mathrm{~min}$. The reaction mixture was stirred at $-45{ }^{\circ} \mathrm{C}$ for 1 hour, slowly warmed (without removing the Dewar) to room temperature, and then stirred overnight at room temperature. Insoluble salts $\left(\mathrm{Et}_{3} \mathrm{~N} \cdot \mathrm{HCl}\right)$ were filtered off and washed with $\mathrm{CH}_{2} \mathrm{Cl}_{2} / \mathrm{Et}_{2} \mathrm{O}$ (1:1). Solvents were then evaporated under vacuum from the liquid layer and a yellow solid was obtained, to which $\mathrm{CH}_{2} \mathrm{Cl}_{2} / \mathrm{Et}_{2} \mathrm{O}$ $(1: 1,40 \mathrm{~mL})$ was added. The insoluble residue was filtered off and the liquid phase was concentrated under vacuum to give a solid that was purified by column chromatography (deactivated silica gel; hexane/acetone 90:10 to 30:70), giving the expected imines in 58\% (for 1a), 52\% (for 1b) and 56\% (for 1c) yields. The corresponding physical and spectroscopic data follow:

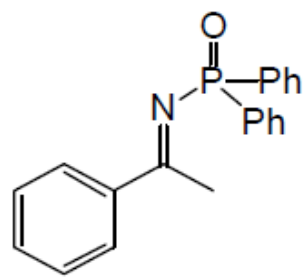

$\mathrm{N}$-(1-Phenylethylidene)diphenylphosphinamide (1a) [29]: pale yellow solid; mp 120-122 ${ }^{\circ} \mathrm{C}$; IR (KBr) 3064, 1637, $1192 \mathrm{~cm}^{-1} ;{ }^{1} \mathrm{H}$ NMR $\left(300 \mathrm{MHz}, \mathrm{CDCl}_{3}\right) \delta 2.97(3 \mathrm{H}, \mathrm{d}, J=2.0 \mathrm{~Hz}), 7.39-7.60(9 \mathrm{H}$, m), 7.92-8.04 (4H, m), $8.09(2 \mathrm{H}, \mathrm{d}, J=7.2 \mathrm{~Hz}) ;{ }^{13} \mathrm{C}$ NMR $(75 \mathrm{MHz}) \delta 26.5(\mathrm{~d}, J=12.7 \mathrm{~Hz}), 127.9$, $128.2(\mathrm{~d}, J=12.9 \mathrm{~Hz}), 128.6,131.1(\mathrm{~d}, J=3.0 \mathrm{~Hz}), 131.3(\mathrm{~d}, J=9.2 \mathrm{~Hz}), 132.2,134.4(\mathrm{~d}$, $J=134.1 \mathrm{~Hz}), 139.1(\mathrm{~d}, J=24.8 \mathrm{~Hz}), 181.2(\mathrm{~d}, J=7.9 \mathrm{~Hz}) ; m / z 319\left(\mathrm{M}^{+}, 53 \%\right), 318$ (23), 277 (12), 242 (14), 202 (11), 201 (100), 125 (28), 77 (50), 51 (21). 


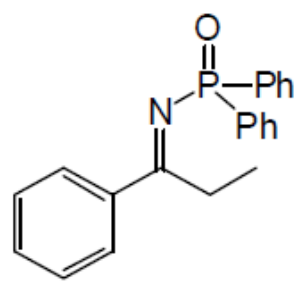

$N$-(1-Phenylpropylidene)diphenylphosphinamide (1b) [44]: white solid; mp 130-132 ${ }^{\circ} \mathrm{C}$; IR (KBr) 3058, 1630, $1190 \mathrm{~cm}^{-1}$; ${ }^{1} \mathrm{H}$ NMR (300 MHz, $\left.\mathrm{C}_{6} \mathrm{D}_{6}\right) \delta 1.06(3 \mathrm{H}, \mathrm{t}, J=7.5 \mathrm{~Hz}), 3.35(2 \mathrm{H}, \mathrm{q}, J=7.5 \mathrm{~Hz})$, 6.99-7.14 (9H, m), 7.83-7.86 (2H, m), 8.23-8.25 (4H, m); ${ }^{13} \mathrm{C}$ NMR (75 MHz, $\left.\mathrm{C}_{6} \mathrm{D}_{6}\right) \delta 13.5,29.0(\mathrm{~d}$, $J=11.9 \mathrm{~Hz}), 128.6(\mathrm{~d}, J=9.0 \mathrm{~Hz}), 128.7(\mathrm{~d}, J=4.8 \mathrm{~Hz}), 131.3(\mathrm{~d}, J=2.9 \mathrm{~Hz}), 132.1,132.2(\mathrm{~d}$, $J=8.7 \mathrm{~Hz}), 132.4(\mathrm{~d}, J=9.2 \mathrm{~Hz}), 136.6(\mathrm{~d}, J=131.3 \mathrm{~Hz}), 138.8(\mathrm{~d}, J=24.3 \mathrm{~Hz}), 186.4(\mathrm{~d}$, $J=7.6 \mathrm{~Hz}) ; \mathrm{m} / z 333\left(\mathrm{M}^{+}, 46 \%\right), 256$ (18), 201 (100), 132 (12), 77 (52).

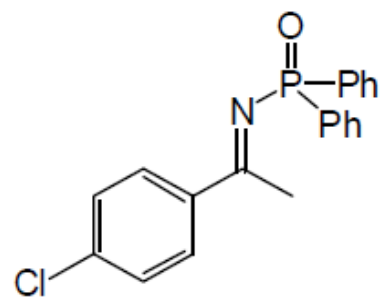

$\mathrm{N}$-[1-(p-Chlorophenyl)ethylidene]diphenylphosphinamide (1c) [44]: white solid; mp 142-144 ${ }^{\circ} \mathrm{C}$; IR (KBr) 3058, 1640, $1199 \mathrm{~cm}^{-1} ;{ }^{1} \mathrm{H}$ NMR $\left(300 \mathrm{MHz}, \mathrm{C}_{6} \mathrm{D}_{6}\right) \delta 2.62(3 \mathrm{H}, \mathrm{d}, J=1.8 \mathrm{~Hz})$, 7.02-7.20 (8H, m), $7.50(2 \mathrm{H}, \mathrm{d}, J=8.8 \mathrm{~Hz}), 8.17-8.26(4 \mathrm{H}, \mathrm{m}) ;{ }^{13} \mathrm{C} \mathrm{NMR}\left(75 \mathrm{MHz}, \mathrm{C}_{6} \mathrm{D}_{6}\right) \delta 22.0(\mathrm{~d}$, $J=12.5 \mathrm{~Hz}), 127.7(\mathrm{~d}, J=11.8 \mathrm{~Hz}), 127.8,128.6,130.5(\mathrm{~d}, J=2.9 \mathrm{~Hz}), 131.1$ (d, $J=8.1 \mathrm{~Hz}), 135.3$ $(\mathrm{d}, J=131.5 \mathrm{~Hz}), 137.4(\mathrm{~d}, J=26.8 \mathrm{~Hz}), 137.5,179.0(\mathrm{~d}, J=7.7 \mathrm{~Hz}) ; m / z 355\left(\mathrm{M}^{+}+2,11 \%\right)$, $353\left(\mathrm{M}^{+}, 39\right), 278$ (21), $276(59), 201$ (100), 154 (12), 152 (38), 77 (43).

\subsection{Procedure for the Asymmetric Transfer Hydrogenation of Imines 1}

A mixture of $\left[\mathrm{RuCl}_{2}(p \text {-cymene })\right]_{2}(15 \mathrm{mg}, 0.025 \mathrm{mmol})$, ligand $\mathbf{L}(0.05 \mathrm{mmol})$ and $i$-PrOH $(2 \mathrm{~mL})$ was heated to $90{ }^{\circ} \mathrm{C}$ (oil bath temperature) for 20 minutes. During this heating period, the initially orange reaction mixture turned into a dark red colour. The reaction was then cooled to $-20{ }^{\circ} \mathrm{C}$, and a solution of the imine $1(0.5 \mathrm{mmol})$ in $i-\mathrm{PrOH}(9 \mathrm{~mL})$ and $t$-BuOK $(2.5 \mathrm{~mL}$ of a $0.1 \mathrm{M}$ solution in $i$-PrOH, $0.25 \mathrm{mmol}$ ) were successively added. The solution was stirred for $1 \mathrm{~h}$ at the same temperature, slowly warmed (without removing the Dewar) to room temperature (ca. $6 \mathrm{~h}$ ) and then stirred at room temperature for $14 \mathrm{~h}$. After completion of the reaction (monitored by TLC), the mixture was passed through a small column of silica gel, the column was eluted with ethyl acetate and the combined organic phases were concentrated under vacuum. The obtained residue was purified by column chromatography (silica gel, hexane/acetone 9:1), yielding the expected reduction products 2 in the yields indicated in Table 2. Phosphinamides $\mathbf{2}$ were analyzed by HPLC on a ChiralCel OD-H column using a $254 \mathrm{~nm}$ UV detector, $10 \% i$ - $\mathrm{PrOH}$ in hexane as eluent and a flow rate of $0.5 \mathrm{~mL} / \mathrm{min}$, giving the enantiomeric excesses (ee's) indicated in Table 2. The retention times were: $16.5(R)$ and $23.4(S)$ for 2a (OD-H column), $13.9(R)$ and $18.9(S)$ for $\mathbf{2 b}(\mathrm{OD}-\mathrm{H}$ column), $12.7(R)$ and $28.1(S)$ for 2c (Chiralpak AS-H column, 20\% $i$-PrOH in hexane as eluent and a flow rate of $1.0 \mathrm{~mL} / \mathrm{min}$ ). For every 
product 2, the absolute configuration of the major enantiomer was assigned according to the HPLC retention times of the two enantiomers described in the literature under the same conditions $[45,46]$. The corresponding physical and spectroscopic data follow:<smiles>C[C@H](NP(=O)(c1ccccc1)c1ccccc1)c1ccccc1</smiles>

(R)- $\boldsymbol{N}$-(1-Phenylethyl)diphenylphosphinamide (2a) [23]: white solid; mp $166-168{ }^{\circ} \mathrm{C} ;[\alpha]^{20}+32.0$ (c 1.1, $\mathrm{CH}_{2} \mathrm{Cl}_{2}, 82 \%$ ee) \{literature [23] $[\alpha]^{20}{ }_{\mathrm{D}}+28.5\left(c 1.0, \mathrm{CH}_{2} \mathrm{Cl}_{2}, 75 \%\right.$ ee $)$; IR (KBr) 3159, 3059, $1179 \mathrm{~cm}^{-1} ;{ }^{1} \mathrm{H}$ NMR $\left(300 \mathrm{MHz}, \mathrm{CDCl}_{3}\right) \delta 1.58(3 \mathrm{H}, \mathrm{d}, J=6.7 \mathrm{~Hz}), 3.14-3.21(1 \mathrm{H}, \mathrm{m}), 4.33-4.48(1 \mathrm{H}$, $\mathrm{m}), 7.25-7.50$ and 7.78-7.95 $(11 \mathrm{H}$ and $4 \mathrm{H}$, respectively, $2 \mathrm{~m}) ;{ }^{13} \mathrm{C} \mathrm{NMR}\left(75 \mathrm{MHz}, \mathrm{CDCl}_{3}\right) \delta 26.3(\mathrm{~d}$, $J=3.0 \mathrm{~Hz}), 51.3,126.0,127.2$, 128.3, 128.4, 128.47, 128.56, 128.59, 131.7, 131.82, 131.86, 132.0, 132.1, 132.5, 132.6, $145.1(\mathrm{~d}, J=6.2 \mathrm{~Hz}) ; m / z 321\left(\mathrm{M}^{+}, 5 \%\right), 307$ (19), 306 (72), 202 (22), 201 (100), 120 (98), 77 (34).<smiles>CC[C@H](NP(=O)(c1ccccc1)c1ccccc1)c1ccccc1</smiles>

(R)- $\boldsymbol{N}$-(1-Phenylpropyl)diphenylphosphinamide (2b) [23]: white solid; mp $153-155{ }^{\circ} \mathrm{C}$; $[\alpha]^{20} \mathrm{D}$ +26.0 (c 1.0, MeOH, 82\% ee) \{literature [23] $[\alpha]^{20}{ }_{\mathrm{D}}+31.3$ (c 1.35, MeOH, 81\% ee) ; IR (KBr) 3145, 3060, $1198 \mathrm{~cm}^{-1} ;{ }^{1} \mathrm{H}$ NMR $\left(300 \mathrm{MHz}, \mathrm{CDCl}_{3}\right) \delta 0.77(3 \mathrm{H}, \mathrm{t}, J=7.5 \mathrm{~Hz}), 1.75-2.10(2 \mathrm{H}, \mathrm{m})$, 3.12-3.35 $(1 \mathrm{H}, \mathrm{m}), 4.02-4.20(1 \mathrm{H}, \mathrm{m}), 7.10-7.55$ and $7.70-7.95(11 \mathrm{H}$ and $4 \mathrm{H}$, respectively, $2 \mathrm{~m})$; ${ }^{13} \mathrm{C} \mathrm{NMR}\left(75 \mathrm{MHz}, \mathrm{CDCl}_{3}\right) \delta 10.5,32.5(\mathrm{~d}, J=3.1 \mathrm{~Hz}), 57.1,126.5,127.1,128.2,128.3,128.4,128.5$, 131.9, 132.5, 132.6, 143.5 (d, $J=5.4 \mathrm{~Hz}) ; m / z 335\left(\mathrm{M}^{+}, 3 \%\right), 307$ (21), 306 (100), 201 (53), 134 (16), $77(22)$.<smiles>C[C@H](NP(=O)(c1ccccc1)c1ccccc1)c1ccc(Cl)cc1</smiles>

(R)- $\mathrm{N}$-[1-(p-Chlorophenyl)ethyl]diphenylphosphinamide (2c) [42]: white solid; $\mathrm{mp} 161-163{ }^{\circ} \mathrm{C}$; $[\alpha]^{20}{ }_{\mathrm{D}}+60.5\left(c 1.0, \mathrm{MeOH}, 80 \%\right.$ ee) $\left\{\right.$ literature for ent-2c $[28][\alpha]^{20}{ }_{\mathrm{D}}-73.4(c 1.14, \mathrm{MeOH}, 94 \%$ ee $\left.)\right\}$; IR (KBr) 3152, 3062, $1189 \mathrm{~cm}^{-1} ;{ }^{1} \mathrm{H} \mathrm{NMR}\left(400 \mathrm{MHz}, \mathrm{CDCl}_{3}\right) \delta 1.54(3 \mathrm{H}, \mathrm{d}, J=6.9 \mathrm{~Hz})$, 3.15-3.34 (1H, m), 4.29-4.45 (1H, m), 7.19-7.30, 7.38-7.51, 7.78-7.93 (4H, 6H and 4H, respectively, $3 \mathrm{~m}) ;{ }^{13} \mathrm{C}$ NMR $\left(100 \mathrm{MHz}, \mathrm{CDCl}_{3}\right) \delta 25.7(\mathrm{~d}, J=3.8 \mathrm{~Hz}), 50.3,127.4,128.2,128.3,128.4,128.6$, 131.4, 132.8, 133.5, $143.5(\mathrm{~d}, J=6.1 \mathrm{~Hz}) ; m / z 357\left(\mathrm{M}^{+}+2,<1 \%\right), 355\left(\mathrm{M}^{+}, 3\right), 340$ (24), $306(100)$, 202 (16), 201 (70), 154 (100), 77 (26). 


\section{Results and Discussion}

In recent years, one of our main research lines has focused on the asymmetric synthesis of chiral amines by enantioselective addition of dialkylzinc reagents to $N$-(diphenylphosphinyl)imines using $\beta$-amino alcohols as ligands [47-49]. Since those ligands have shown to give excellent results in the ruthenium-catalyzed asymmetric transfer hydrogenation of ketones [12-19] and $N$-sulfinylimines [38-41] in isopropyl alcohol, we decided to investigate if they could also be applied to the reduction of $N$-phosphinyl ketimines by the same methodology. One of the most noteworthy chiral $\beta$-amino alcohols in the ATH of both ketones and $N$-sulfinyl imines is cis-1-amino-2-indanol [50]. Due to this, we chose (1S,2R)-1-amino-2-indanol $\mathbf{L 1}$ as a test ligand for the ruthenium-catalyzed transfer hydrogenation of the $N$-phosphinyl imine derived from acetophenone 1a (Table 1). The ruthenium catalyst was prepared by refluxing a mixture of the ruthenium dimer $\left[\mathrm{RuCl}_{2}(p \text {-cymene })\right]_{2}$ and $\mathbf{L} \mathbf{1}$ in isopropyl alcohol.

Table 1. Ruthenium-catalyzed asymmetric transfer hydrogenation of $N$-(diphenylphosphinyl)-ketimine 1a in isopropyl alcohol. Optimization of the reaction conditions ${ }^{a}$.

$\left[\mathrm{RuCl}_{2}(p \text {-cymene })\right]_{2}$ (cat.)

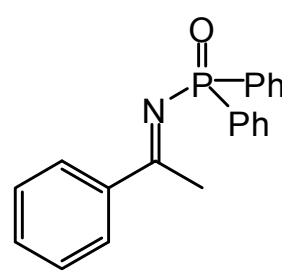

$1 \mathbf{a}$

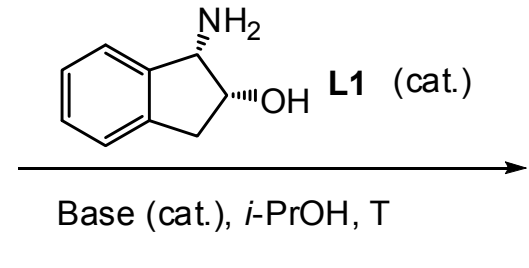

Base (cat.), $i-\mathrm{PrOH}, \mathrm{T}$

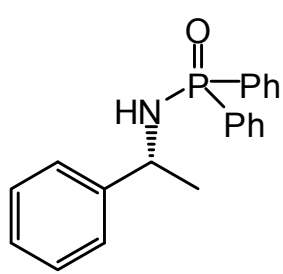

$2 \mathbf{a}$

\begin{tabular}{|c|c|c|c|c|c|c|c|c|}
\hline \multirow{2}{*}{ Entry } & \multirow{2}{*}{$\begin{array}{c}\text { Ru-dimer } \\
\text { (mol\%) }\end{array}$} & \multirow{2}{*}{$\begin{array}{c}\text { L1 } \\
(\mathrm{mol} \%)\end{array}$} & \multicolumn{2}{|c|}{ Base } & \multirow{2}{*}{$\mathbf{T}\left({ }^{\circ} \mathbf{C}\right)$} & \multirow{2}{*}{ t (h) } & \multicolumn{2}{|c|}{ Product 2a } \\
\hline & & & Base & mol\% & & & Yield $^{b}(\%)$ & $\mathrm{ee}^{c}(\%)$ \\
\hline 1 & 5 & 20 & $\mathrm{KOH}$ & 50 & 25 & 5 & 56 & 66 \\
\hline 2 & 5 & 10 & $\mathrm{KOH}$ & 50 & 25 & 3 & 76 & 72 \\
\hline 3 & 5 & 5 & $\mathrm{KOH}$ & 50 & 25 & 6 & 55 & 64 \\
\hline 4 & 5 & 10 & $\mathrm{KOH}$ & 75 & 25 & 3 & 84 & 66 \\
\hline 5 & 5 & 10 & $\mathrm{KOH}$ & 25 & 25 & 6 & 78 & 66 \\
\hline 6 & 5 & 10 & $\mathrm{LiOH}$ & 50 & 25 & 5 & 63 & 70 \\
\hline 7 & 5 & 10 & $\mathrm{NaOH}$ & 50 & 25 & 3 & 55 & 68 \\
\hline 8 & 3 & 6 & $\mathrm{KOH}$ & 30 & 25 & 18 & 53 & 74 \\
\hline 9 & 5 & 10 & $\mathrm{KOH}$ & 50 & 50 & 2 & 74 & 60 \\
\hline 10 & 5 & 10 & $\mathrm{KOH}$ & 50 & 0 & 29 & 48 & 78 \\
\hline $11^{d}$ & 5 & 10 & $\mathrm{KOH}$ & 50 & 0 to 25 & 19 & 70 & 78 \\
\hline $12^{d}$ & 5 & 10 & $\mathrm{KOH}$ & 50 & -20 to 25 & 22 & 80 & 80 \\
\hline $13^{d}$ & 5 & 10 & $t$-BuOK & 50 & -20 to 25 & 20 & 87 & 82 \\
\hline $14^{d}$ & 5 & 10 & $t$-BuOK & 50 & -40 to 25 & 20 & 85 & 78 \\
\hline
\end{tabular}

${ }^{a}$ The solution of the imine $1 \mathrm{a}(0.5 \mathrm{mmol})$ in $i$-PrOH $(9 \mathrm{~mL})$ was added to a solution of the ruthenium catalyst [prepared by refluxing a mixture of $\left[\mathrm{RuCl}_{2}(p \text {-cymene })\right]_{2}$ and amino alcohol $\mathbf{L 1}$ in $i$-PrOH $\left.(2 \mathrm{~mL})\right]$ at the temperature indicated. Then, the base (as a $0.1 \mathrm{M}$ solution in $i-\mathrm{PrOH}$ ) was added and the reaction mixture was stirred for the time indicated. ${ }^{b}$ Isolated yield after purification by column chromatography (silica gel, hexane/acetone: 9/1) based on the starting imine 1a. ${ }^{c}$ Determined by HPLC using a ChiralCel OD-H column. The $R$-enantiomer was the major one in all cases. ${ }^{d}$ The reaction mixture was stirred at the initial temperature for $1 \mathrm{~h}$ and then it was allowed to gradually reach room temperature. 
Since a proportion Ru-dimer:aminoalcohol:base $=1: 4: 10$ is common for the ATH of ketones, we chose that proportion as the starting point of our study, using $5 \mathrm{~mol} \%$ of the Ru-dimer. Under those conditions, the Ru complex bearing $\mathbf{L 1}$ was able to reduce the imine $\mathbf{1 a}$ in isopropyl alcohol in the presence of potassium hydroxide, affording product 2a in a moderate yield and with $66 \%$ ee after stirring for $5 \mathrm{~h}$ at room temperature (Table 1, entry 1). This promising result encouraged us to try to optimize the reaction conditions. First, the amount of $\mathbf{L 1}$ was reduced keeping the loadings of Ru-dimer and base constant and we found that both yield and ee improved when the ratio Ru-dimer:L1 was 1:2 (compare entries 1-3 in Table 1). Hence, we decided to keep that ratio in the following tests. Next, the loading of base was evaluated and a decrease in the enantioselectivity, in comparison with the results of entry 2, was observed when the amount of potassium hydroxide was either increased to $75 \mathrm{~mol} \%$ (Table 1, entry 4) or decreased to $25 \mathrm{~mol} \%$ (Table 1, entry 5). Since the optimum ratio Ru-dimer:L1:base seemed to be 1:2:10, it was maintained in further experiments. A different metallic cation in the base did not cause any noticeable effect on the enantioselectivity: lithium and sodium hydroxides gave almost the same ee's as potassium hydroxide, the yield being higher with the latter (compare entries 2, 6 and 7 in Table 1). We tried to reduce the amount of the Ru-dimer to $3 \mathrm{~mol} \%$, but this considerably slowed down the transfer hydrogenation process and resulted in a lower yield of $\mathbf{2 a}$, although the enantioselectivity did not vary (compare entries 2 and 8 in Table 1).

The effect of the temperature was also studied. The ee decreased to $60 \%$ when the reaction was performed at $50{ }^{\circ} \mathrm{C}$ (Table 1, entry 9). A decrease of the temperature to $0{ }^{\circ} \mathrm{C}$ drastically lengthened the reaction time and, furthermore, the yield decreased to $48 \%$ (Table 1, entry 10). However, the enantioselection of the process slightly improved to $78 \%$ ee. In order to try to improve the yield, the reaction was repeated and an upward temperature gradient was applied: after stirring for $1 \mathrm{~h}$ at $0{ }^{\circ} \mathrm{C}$, the reaction was allowed to gradually reach room temperature. We were delighted to see that, under these conditions, a 70\% yield was obtained with no detriment to the enantioselectivity (Table 1, entry 11). A slight improvement of both yield and enantioselectivity were observed when the initial temperature was $-20{ }^{\circ} \mathrm{C}$ instead of $0{ }^{\circ} \mathrm{C}$ (Table 1, entry 12). Since in our previous studies concerning the ATH of $N$-(tert-butylsulfinyl)imines [38-41] we found that potassium tert-butoxide was a more convenient base than potassium hydroxide, we decided to evaluate the former in the ATH of phosphinylimine 1a and we obtained a further improvement, giving $87 \%$ yield and $82 \%$ ee (Table 1 , entry 13). A decrease of the initial temperature to $-40{ }^{\circ} \mathrm{C}$ slightly reduced both the yield and the enantiomeric excess (Table 1, entry 14). After having performed this screening, we chose the conditions shown in entry 13 as the optimal ones.

The influence of the arene ligand in the ruthenium catalyst was also studied and we found that the use of $\left[\mathrm{RuCl}_{2} \text { (benzene) }\right]_{2}$ instead of $\left[\mathrm{RuCl}_{2}(p \text {-cymene })\right]_{2}$ almost completely prevented any asymmetric induction, the ee of the product $\mathbf{2 a}$ being only $8 \%$.

Once we had determined the optimum reaction conditions, we decided to test some other chiral $\beta$-amino alcohols with the aim of evaluating the influence of the ligand structure on the success of the ATH process. Amino alcohols $(1 R, 2 S)$-norephedrine L2, $(1 R, 2 S)$-2-amino-1,2-diphenylethanol $\mathbf{L 3}$ and prolinols $\mathbf{L} 4$ and $\mathbf{L 5}$ were tested as potential ligands, and the results are summarized in Table 2. The ruthenium complex bearing norephedrine $\mathbf{L 2}$ was able to reduce imine 1a, though the results concerning both yield and enantioselectivity were rather poor (Table 2, entry 2). When the ATH reaction was carried out using ligand $\mathbf{L 3}$, the reduction product was obtained in only $39 \%$ yield and 
with a moderate ee. Therefore, ligands $\mathbf{L 2}$ and $\mathbf{L 3}$ have shown to be clearly inferior to $\mathbf{L 1}$ (compare entries 1 to 3 in Table 2). This drop in enantioselectivity could be due to the fact that (1S,2R)-1-amino2-indanol $\mathbf{L} 1$ has a more rigid structure than ligands $\mathbf{L} 2$ or $\mathbf{L 3}$. Therefore, it seems that the rigidity of the $\beta$-amino alcohol seems to be very convenient for achieving good enantioselectivities in this ATH process. Finally, in agreement with our observations in the ATH of sulfinylimines [38-41], a ligand with a free primary amino group led to higher enantioselectivities than other ligands bearing secondary amino groups: when the ligands with a prolinol backbone $\mathbf{L} \mathbf{4}$ and $\mathbf{L 5}$ were tested, either no reduction product or only traces of it could be detected after working-up the reaction (Table 2, entries 4 and 5).

Table 2. Test of different amino alcohols as chiral ligands for the ruthenium-catalyzed transfer hydrogenation of $N$-phosphinylimines $\mathbf{1}^{a}$.
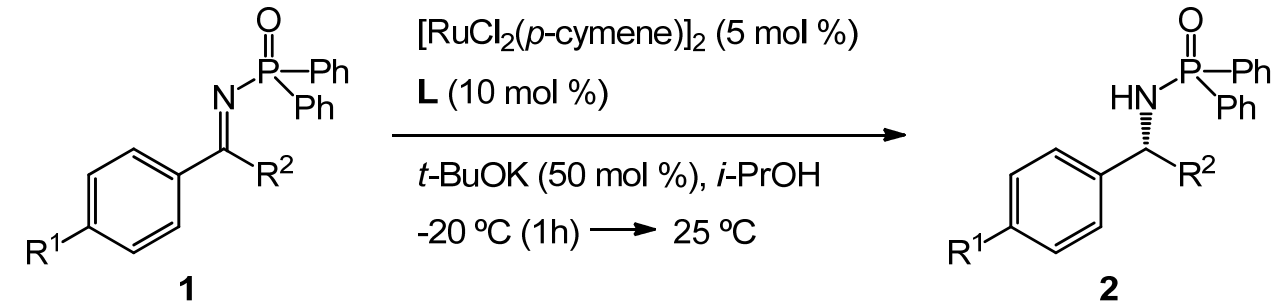<smiles>N[C@H]1c2ccccc2CC1O</smiles>

L1<smiles>CC(N)C(O)c1ccccc1</smiles>

L2<smiles>N[C@@H](c1ccccc1)[C@H](O)c1ccccc1</smiles>

L3<smiles>OCC1CCCN1</smiles>

L4

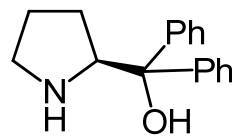

L5

\begin{tabular}{|c|c|c|c|c|c|c|c|c|}
\hline \multirow{2}{*}{ Entry } & \multicolumn{3}{|c|}{ Imine } & \multirow{2}{*}{ Ligand } & \multirow{2}{*}{ t (h) } & \multicolumn{3}{|c|}{ Product 2} \\
\hline & No. & $\mathbf{R}^{1}$ & $\mathbf{R}^{2}$ & & & No. & Yield $^{b}(\%)$ & $e e^{c}(\%)$ \\
\hline 1 & 1a & $\mathrm{H}$ & $\mathrm{Me}$ & L1 & 20 & $\mathbf{2 a}$ & 87 & 82 \\
\hline 2 & 1a & $\mathrm{H}$ & $\mathrm{Me}$ & $\mathbf{L} 2$ & 20 & $2 a$ & 49 & 48 \\
\hline 3 & $1 \mathbf{a}$ & $\mathrm{H}$ & $\mathrm{Me}$ & $\mathbf{L 3}$ & 20 & $2 a$ & 39 & 53 \\
\hline 4 & $1 \mathbf{a}$ & $\mathrm{H}$ & $\mathrm{Me}$ & L4 & 22 & $2 \mathbf{a}$ & $\simeq^{d}$ & - \\
\hline 5 & $1 \mathbf{a}$ & $\mathrm{H}$ & $\mathrm{Me}$ & L5 & 25 & $2 \mathbf{a}$ & $-^{e}$ & - \\
\hline 6 & $1 \mathrm{~b}$ & $\mathrm{H}$ & Et & L1 & 20 & $2 b$ & 90 & 82 \\
\hline 7 & $1 \mathrm{c}$ & $\mathrm{Cl}$ & $\mathrm{Me}$ & L1 & 20 & $2 \mathrm{c}$ & 85 & 80 \\
\hline
\end{tabular}

${ }^{a}$ The solution of the imine $1(0.5 \mathrm{mmol})$ in $i-\mathrm{PrOH}(9 \mathrm{~mL})$ was added to a solution of the ruthenium catalyst [prepared by refluxing a mixture of $\left[\mathrm{RuCl}_{2}(p \text {-cymene })\right]_{2}(0.025 \mathrm{mmol})$ and amino alcohol $\mathbf{L}(0.05 \mathrm{mmol})$ in $i$-PrOH $(2 \mathrm{~mL})]$ at $-20^{\circ} \mathrm{C}$. Then, $t$-BuOK $(0.25 \mathrm{mmol}$, as a $0.1 \mathrm{M}$ solution in $i$-PrOH $)$ was added and the reaction mixture was stirred at the same temperature for $1 \mathrm{~h}$ and then it was allowed to gradually reach room temperature. ${ }^{b}$ Isolated yield after purification by column chromatography (silica gel, hexane/acetone: 9/1) based on the starting imine 1. ${ }^{c}$ Determined by HPLC using a ChiralCel OD-H column or a Chiralpak AS-H column. The $R$-enantiomer was the major one in all cases. ${ }^{d}$ Only traces of the product were detected in the crude reaction mixture. ${ }^{\mathrm{e}}$ No reduction product was detected in the crude reaction mixture.

After having established that L1 was the ligand of choice, we tested two more imines as substrates. The asymmetric transfer hydrogenation of imines $\mathbf{1 b}$ and $\mathbf{1 c}$, derived from propiophenone and 4-chloroacetophenone respectively, under the conditions of entry 13 in Table 1 gave the expected phosphinamides $\mathbf{2 b}$ and $\mathbf{2 c}$ in high yields and with ee's of 82 and 80\%, respectively (Table 2, entries 6 and 7). 


\section{Conclusions}

In conclusion, we have developed a new efficient procedure for the reduction of prochiral $N$-(diphenylphosphinyl)ketimines through a ruthenium-catalyzed asymmetric transfer hydrogenation process in isopropyl alcohol using a $\beta$-amino alcohol as a chiral ligand. The rigid structure present in $(1 S, 2 R)$-1-amino-2-indanol seems to be very convenient in order to achieve good enantiomeric excesses. The arene ligand on the ruthenium complex also has an influence on the stereochemical outcome of the reaction. Since the phosphinyl group can easily be removed under mild acidic conditions, this procedure represents an efficient method to synthesize optically enriched chiral primary amines. Further efforts to improve the enantioselectivity and to extend the substrate scope of this new ATH process are currently underway in our laboratory.

\section{Acknowledgements}

This work was generously supported by the Spanish Ministerio de Ciencia e Innovación (MICINN; Grant No. CONSOLIDER INGENIO 2010, CSD2007-00006, CTQ2007-65218, and CTQ11-24151) and the Generalitat Valenciana (PROMETEO/2009/039 and FEDER). Óscar Pablo thanks the Spanish Ministerio de Educación for a predoctoral fellowship (Grant No. AP2008-00989). We also thank MEDALCHEMY S.L. for a gift of chemicals.

\section{References and Notes}

1. Jacques, J.; Collet, A.; Wilen, S.H. Enantiomers, Racemates and Resolution; John Wiley \& Sons: New York, NY, USA, 1981.

2. Juaristi, E.; Escalante, J.; León-Romo, J.L.; Reyes, A. Recent applications of $\alpha$-phenylethylamine $(\alpha$-PEA) in the preparation of enantiopure compounds. Part 1. Incorporation in chiral catalysts. Part 2. $\alpha$-PEA and derivatives as resolving agents. Tetrahedron: Asymmetry 1998, 9, 715-740.

3. Fogassy, E.; Nógrádi, M.; Kozma, D.; Egri, G.; Pálovics, E.; Kiss, V. Optical resolution methods. Org. Biomol. Chem. 2006, 4, 3011-3030.

4. Faigl, F.; Fogassy, E.; Nógrádi, M.; Pálovics, E.; Schindler, J. Strategies in optical resolution: A practical guide. Tetrahedron: Asymmetry 2008, 19, 519-536.

5. Nugent, T.C. Chiral Amine Synthesis. Methods, Developments and Applications; Wiley-VCH: Weinheim, Germany, 2010.

6. Whitesell, J.K. C 2 Symmetry and asymmetric induction. Chem. Rev. 1989, 89, 1581-1590.

7. Lucet, D.; Le Gall, T.; Mioskowski, C. The chemistry of vicinal diamines. Angew. Chem. Int. Ed. 1998, 37, 2580-2627.

8. Waldmann, H. C2-symmetric amines as chiral auxiliaries. In Organic Synthesis Highlights II; Waldmann, H., Ed.; Wiley-VCH Verlag GmbH: Weinheim, Germany, 2008.

9. Braese, S.; Baumann, T.; Dahmen, S.; Vogt, H. Enantioselective catalytic syntheses of $\alpha$-branched chiral amines. Chem. Commun. 2007, 1881-1890.

10. Nugent, T.C.; El-Shazly, M. Chiral amine synthesis. Recent developments and trends for enamide reduction, reductive amination, and imine reduction. Adv. Synth. Catal. 2010, 352, 753-819. 
11. Gladiali, S.; Alberico, E. Asymmetric transfer hydrogenation: Chiral ligands and applications. Chem. Soc. Rev. 2006, 35, 226-236.

12. Noyori, R.; Hashiguchi, S. Asymmetric transfer hydrogenation catalyzed by chiral ruthenium complexes. Acc. Chem. Res. 1997, 30, 97-102.

13. Palmer, M.J.; Wills, M. Asymmetric transfer hydrogenation of $\mathrm{C}=\mathrm{O}$ and $\mathrm{C}=\mathrm{N}$ bonds. Tetrahedron 1999, 10, 2045-2061.

14. Wills, M.; Palmer, M.; Smith, A.; Kenny, J.; Walsgrove, T. Recent developments in the area of asymmetric transfer hydrogenation. Molecules 2000, 5, 4-18.

15. Clapham, S.E.; Hadzovic, A.; Morris, R.H. Mechanisms of the $\mathrm{H}_{2}$-hydrogenation and transfer hydrogenation of polar bonds catalyzed by ruthenium hydride complexes. Coord. Chem. Rev. 2004, 248, 2201-2237.

16. Ikariya, T.; Blacker, A.J. Asymmetric transfer hydrogenation of ketones with bifunctional transition metal-based molecular catalysts. Acc. Chem. Res. 2007, 40, 1300-1308.

17. Wang, C.; Wu, X.; Xiao, J. Broader, greener, and more efficient: Recent advances in asymmetric transfer hydrogenation. Chem. Asian J. 2008, 3, 1750-1770.

18. Wills, M. Imino reductions by transfer hydrogenation. In Modern Reduction Methods; Andersson, P.G., Munslow, I.J., Eds.; Wiley-VCH: Weinheim, Germany, 2008; pp. 271-296.

19. Malacea, R.; Poli, R.; Manoury, E. Asymmetric hydrosilylation, transfer hydrogenation, and hydrogenation of ketones catalyzed by iridium complexes. Coord. Chem. Rev. 2010, 254, 729-752.

20. Spindler, F.; Blaser, H.-U. Enantioselective hydrogenation of $\mathrm{C}=\mathrm{N}$ functions and enamines. Handb. Homog. Hydrog. 2007, 3, 1193-1214.

21. Fabrello, A.; Bachelier, A.; Urrutigoïty, M.; Kalck, P. Mechanistic analysis of the transition metal-catalyzed hydrogenation of imines and functionalized enamines. Coord. Chem. Rev. 2010, 254, 273-287.

22. Krzyzanowska, B.; Stec, W.J. A new approach to the synthesis of primary amines, isothiocyanates, and 1-aminoalkanephosphonates via $N$-phosphinyl aldoximes and ketoximes. Synthesis 1978, 521-524.

23. Andersson, P.G.; Guijarro, D.; Tanner, D. Preparation and use of aziridino alcohols as promoters for the enantioselective addition of dialkylzinc reagents to $\mathrm{N}$-(diphenylphosphinoyl) imines. $J$. Org. Chem. 1997, 62, 7364-7375.

24. For a review on the use of $N$-phosphinoylimines in stereoselective synthesis, see: Weinreb, S.M.; Orr, R.K. N-Phosphinoylimines: An emerging class of reactive intermediates for stereoselective organic synthesis. Synthesis 2005, 1205-1227.

25. Vilaivan, T.; Bhanthumnavin, W.; Sritana-Anant, Y. Recent advances in catalytic asymmetric addition to imines and related $\mathrm{C}=\mathrm{N}$ systems. Curr. Org. Chem. 2005, 9, 1315-1392.

26. Spindler, F.; Blaser, H.-U. The highly enantioselective hydrogenation of $N$ diphenylphosphinylketimines with cationic Rh ferrocenyldiphosphine catalysts. Adv. Synth. Catal. 2001, 343, 68-70.

27. Wang, Y.-Q.; Zhou, Y.-G. Highly enantioselective Pd-catalyzed asymmetric hydrogenation of $N$-diphenylphosphinyl ketimines. Synlett 2006, 1189-1192. 
28. Wang, Y.-Q.; Lu, S.-M.; Zhou, Y.-G. Highly enantioselective Pd-catalyzed asymmetric hydrogenation of activated imines. J. Org. Chem. 2007, 72, 3729-3734.

29. Lipshutz, B.H.; Shimizu, H. Copper(I)-catalyzed asymmetric hydrosilylations of imines at ambient temperatures. Angew. Chem. Int. Ed. 2004, 43, 2228-2230.

30. Nolin, K.A.; Ahn, R.W.; Toste, F.D. Enantioselective reduction of imines catalyzed by a rhenium(V)-oxo complex. J. Am. Chem. Soc. 2005, 127, 12462-12463.

31. Park, B.-M.; Mun, S.; Yun, J. Zinc-catalyzed enantioselective hydrosilylation of imines. Adv. Synth. Catal. 2006, 348, 1029-1032.

32. Bandini, M.; Melucci, M.; Piccinelli, F.; Sinisi, R.; Tommasi, S.; Umani-Ronchi, A. New chiral diamino-bis(tert-thiophene): An effective ligand for $\mathrm{Pd}$ - and $\mathrm{Zn}$-catalyzed asymmetric transformations. Chem. Commun. 2007, 4519-4521.

33. Nolin, K.A.; Ahn, R.W.; Kobayashi, Y.; Kennedy-Smith, J.J.; Toste, F.D. Enantioselective reduction of ketones and imines catalyzed by (CN-Box)ReV-oxo complexes. Chem. Eur. J. 2010, 16, 9555-9562.

34. Graves, C.R.; Scheidt, K.A.; Nguyen, S.T. Enantioselective MSPV reduction of ketimines using 2-propanol and (BINOL)Al(III). Org. Lett. 2006, 8, 1229-1232.

35. Yamada, T.; Nagata, T.; Sugi, K.D.; Yorozu, K.; Ikeno, T.; Ohtsuka, Y.; Miyazaki, D.; Mukaiyama, T. Enantioselective borohydride reduction catalyzed by optically active cobalt complexes. Chem. Eur. J. 2003, 9, 4485-4509.

36. Dai-Ho, G.; Mariano, P.S. Novel photochemical-diradical cyclization methods for protoberberine alkaloid synthesis. Preparation of $( \pm)$-xylopinine and $( \pm)$-stylopine. J. Org. Chem. 1987, 52, 704-706.

37. Kwak, S.H.; Lee, S.A.; Lee, K.-I. Highly enantioselective Rh-catalyzed transfer hydrogenation of $N$-sulfonyl ketimines. Tetrahedron 2010, 21, 800-804.

38. Guijarro, D.; Pablo, O.; Yus, M. Ruthenium-catalysed asymmetric transfer hydrogenation of $N$ (tert-butanesulfinyl)imines. Tetrahedron Lett. 2009, 50, 5386-5388.

39. Guijarro, D.; Pablo, O.; Yus, M. Asymmetric synthesis of chiral primary amines by transfer hydrogenation of $N$-(tert-butanesulfinyl)ketimines. J. Org. Chem. 2010, 75, 5265-5270.

40. Guijarro, D.; Pablo, O.; Yus, M. Achiral $\beta$-amino alcohols as efficient ligands for the rutheniumcatalyzed asymmetric transfer hydrogenation of sulfinylimines. Tetrahedron Lett. 2011, 52, 789-791.

41. Pablo, O.; Guijarro, D.; Kovács, G.; Lledós, A.; Ujaque, G.; Yus, M. A versatile Ru catalyst for the asymmetric transfer hydrogenation of both aromatic and aliphatic sulfinylimines. Chem. Eur. J. 2012, in press.

42. Zhou, S.; Fleischer, S.; Junge, K.; Das, S.; Addis, D.; Beller, M. Enantioselective synthesis of amines: General, efficient iron-catalyzed asymmetric transfer hydrogenation of imines. Angew. Chem. Int. Ed. 2010, 49, 8121-8125.

43. Zhang, G.; Wen, X.; Wang, Y.; Mo, W.; Ding, C. Sodium nitrite catalyzed aerobic oxidative deoximation under mild conditions. J. Org. Chem. 2011, 76, 4665-4668.

44. Masumoto, S.; Usuda, H.; Suzuki, M.; Kanai, M.; Shibasaki, M. Catalytic enantioselective strecker reaction of ketoimines. J. Amer. Chem. Soc. 2003, 125, 5634-5635. 
45. Almansa, R.; Guijarro, D.; Yus, M. Enantioselective addition of dialkylzinc reagents to $N$-(diphenylphosphinoyl)imines catalyzed by $\beta$-aminoalcohols with the prolinol skeleton. Tetrahedron: Asymmetry 2007, 18, 2828-2840 (retention times of the two enantiomers of compounds $\mathbf{2 a}$ and $\mathbf{2 b}$ ).

46. See reference 28 for the retention times of the two enantiomers of compound $\mathbf{2 c}$.

47. Almansa, R.; Guijarro, D.; Yus, M. N-Benzylprolinol: An efficient catalyst for the enantioselective addition of dialkylzinc reagents to $N$-(diphenylphosphinoyl)imines. Tetrahedron: Asymmetry 2007, 18, 896-899.

48. Almansa, R.; Guijarro, D.; Yus, M. Enantioselective addition of dialkylzinc reagents to $N$-(diphenylphosphinoyl)imines catalyzed by $\beta$-amino alcohols with the prolinol skeleton. Tetrahedron: Asymmetry 2007, 18, 2828-2840.

49. Almansa, R.; Guijarro, D.; Yus, M. Microwave-accelerated enantioselective addition of dialkylzinc reagents to $N$-(diphenylphosphinoyl)imines catalyzed by $\beta$-amino alcohols with the prolinol skeleton. Tetrahedron: Asymmetry 2008, 19, 1376-1380.

50. For an excellent review on the use of cis-aminoindanol in asymmetric synthesis see: Gallou, I.; Senanayake, C.H. cis-1-Amino-2-indanol in drug design and applications to asymmetric processes. Chem. Rev. 2006, 106, 2843-2874.

(C) 2012 by the authors; licensee MDPI, Basel, Switzerland. This article is an open access article distributed under the terms and conditions of the Creative Commons Attribution license (http://creativecommons.org/licenses/by/3.0/). 